Thorax (1970), 25, 748.

\title{
Arthritis and arthralgia in infection with Mycoplasma pneumoniae
}

\author{
M.C. J ONES \\ Brompton Hospital, London, S.W.3
}

Joint involvement following infection with Mycoplasma pneumoniae is extremely uncommon. Four patients are presented in whom joint symptoms occurred, giving rise to diagnostic difficulties in three. It is suggested that these manifestations were due to M. pneumoniae.

Mycoplasma pneumoniae, first identified as the cause of Eaton agent pneumonia in 1962 by Chanock, Hayflick, and Barile, remains the only species of mycoplasma proven to be a human pathogen (Griffin and Crawford, 1969). It attacks mainly the respiratory system but is also a recognized cause of acute haemolytic anaemia (Peterson, Ham, and Finland, 1943) and erythema multiforme (Gordon and Lyell, 1969). Involvement of the ear, heart and central nervous system has also been described (Lambert, 1968a), and recently three cases with joint involvement have been reported (Lambert, 1968b). A further four cases are now presented.

\section{CASE REPORTS}

CASE 1 (Table) A girl of 14 years presented with fever, malaise, headache and sore throat. She was treated with penicillin but remained unwell. Five weeks later she developed pleurisy with pain and stiffness in both knees: a week later she became increasingly ill with severe headache, rigors, fever rising to $105^{\circ} \mathrm{F}$. and mucopurulent sputum. On examination there was evidence of tonsillitis. Both knees were painful on movement but otherwise appeared normal. The chest was clear.

Investigations Haemoglobin 12.6 g./100 ml., WBC $6,200 / \mathrm{cu}$. mm., ESR $37 \mathrm{~mm}$. (Westergren). Sputum sterile on culture ; blood cultures negative ; antistreptolysin $O$ (ASO) titre less than 200 units $/ \mathrm{ml}$. A chest radiograph showed consolidation involving the anterior segment of the left upper lobe. Initial complement fixation test (CFT) to $M$. pneumoniae showed a titre of less than 1 in 5 together with a cold agglutinin titre (CAT) of 1 in 16 at $4^{\circ} \mathrm{C}$.

Treatment with ampicillin was ineffective, the temperature remaining at $102^{\circ} \mathrm{F}$. After four days tetracycline was started, the temperature returned to normal within 48 hours, and the pneumonia resolved radiologically within four weeks. Cultures of the sputum yielded $M$. pneumoniae after two weeks' incubation, when the CFT had risen to 1 in 320 . The patient made a good clinical recovery but continued to complain of pain and stiffness in both knees and had difficulty in walking for three months.

CASE 2 (Table) A woman aged 62 years, a mild chronic bronchitic, was admitted to hospital with a 10-day history of fever, malaise, headache and productive cough. The symptoms had failed to respond to either lincomycin or tetracycline. On examination

T A B L E

\begin{tabular}{|c|c|c|c|c|c|c|c|c|}
\hline \multirow{2}{*}{ Case } & \multirow{2}{*}{ Sex } & \multirow{2}{*}{ Age } & \multirow{2}{*}{ Affected Joints } & \multicolumn{2}{|c|}{ Complement Fixation Tests } & \multicolumn{2}{|c|}{ Cold Agglutinin Test } & \multirow{2}{*}{$\begin{array}{l}\text { ASO } \\
\text { Titre }\end{array}$} \\
\hline & & & & $1 \mathrm{st}$ & 2nd & $1 \mathrm{st}$ & 2nd & \\
\hline \multirow{2}{*}{$\begin{array}{l}1 \\
2\end{array}$} & \multirow{2}{*}{$\begin{array}{l}\mathbf{F} \\
\mathbf{F}\end{array}$} & \multirow{2}{*}{$\begin{array}{l}14 \\
62\end{array}$} & \multirow{4}{*}{$\begin{array}{l}\text { Knees } \\
\text { Shoulders, elbows, knees, } \\
\text { hands } \\
\text { Wrists, elbows, shoulders, } \\
\text { knees, ankles } \\
\text { Elbows, knees, ankles }\end{array}$} & $<5$ & $>320^{1}$ & 16 & - & $<200$ \\
\hline & & & & 80 & 320 & $<10$ & 160 & - \\
\hline 3 & $\mathbf{M}$ & 32 & & 128 & 64 & & & 250 \\
\hline 4 & $\mathbf{M}$ & 15 & & 1,280 & 2,560 & $>1,280$ & 160 & 800 \\
\hline \multirow[t]{2}{*}{$\begin{array}{l}\text { L1 } \\
\text { L2 } \\
\text { L3 }\end{array}$} & \multirow[t]{2}{*}{$\begin{array}{l}\mathbf{M} \\
\mathbf{M} \\
\mathbf{M}\end{array}$} & \multirow[t]{2}{*}{$\begin{array}{l}17 \\
11 \\
14\end{array}$} & \multirow{2}{*}{$\begin{array}{l}\text { Knees, ankle } \\
\text { Knee, ankle } \\
\text { Hands, shoulders, knees, } \\
\text { feet }\end{array}$} & $\begin{array}{r}1,280 \\
80\end{array}$ & $\begin{array}{r}90 \\
1,280\end{array}$ & $5 \overline{12}$ & $=$ & $\begin{array}{l}200 \\
100\end{array}$ \\
\hline & & & & 320 & 20 & 32 & - & 230 \\
\hline
\end{tabular}

$1 M$. pneumoniae isolated from sputum.

Table also includes cases L1-3 taken from Lambert (1968b).

All cases except 3 had pneumonia. 
she was ill, drowsy and dehydrated with a temperature of $102 \cdot 6^{\circ}$ F. Apart from bilateral crepitations in the chest there were no other abnormal findings.

Investigations Haemoglobin 12.7 g. $/ 100 \mathrm{ml}$., WBC $12,000 / \mathrm{cu}$. mm., ESR $120 \mathrm{~mm}$. (Westergren). Sputum culture negative. A chest radiograph showed bilateral bronchopneumonia, confluent in the right upper lobe.

Next day she complained of pain and stiffness in the elbows, shoulders and knees followed by painful swelling of the phalangeal joints of both hands. Three days later her haemoglobin had fallen to 8.2 g. $/ 100$ $\mathrm{ml}$. and showed evidence of auto-agglutination in that cold haemagglutination was present. The reticulocyte count $(5 \%)$, serum bilirubin $(0.9 \mathrm{mg} . \%)$ and transaminases (SGOT 65 i.u., SGPT 47 i.u.-normal 0-40 i.u.) were elevated whilst her CAT rose from less than 1 in 10 to 1 in 160 in 8 days. Initial CFT to $M$. pneumoniae was 1 in 80 : the sheep cell differential agglutination test (DAT) and Latex tests were both negative.

Though her temperature returned to normal on the fifth day whilst still on tetracycline, her general condition remained poor and a chest radiograph showed extension of the consolidation in the right lung. By the ninth day her CFT had risen to 1 in 320 . In the following two weeks she made a slow recovery and was discharged home continuing to complain of pain and stiffness in the joints, particularly in the right shoulder. The radiological changes resolved within four weeks and her ESR on discharge was $29 \mathrm{~mm}$. (Westergren). Five months later the CFT had fallen to $1: 20$, and she still had some discomfort in the right shoulder and knee.

CASE 3 (Table) A man aged 32 years was admitted to hospital with a five weeks' history of pain, stiffness and swelling of both knees spreading over the next four weeks to involve the shoulders, elbows, ankles and wrists. He then developed a sore throat followed by an itchy erythematous rash over the back, abdomen, and legs; he had not received any drug treatment.

On examination he was afebrile though flushed and with injected fauces. The left wrist was slightly swollen because of a joint effusion and there was a subcutaneous nodule over the extensor aspect of the elbow. There were no signs in the previously affected joints other than some residual tenderness. There were no other abnormal findings. Pulse rate was $100 /$ minute.

Investigations Haemoglobin 14.3 g./100 ml., WBC $9,600 / \mathrm{cu}$. mm., ESR $53 \mathrm{~mm}$. (Westergren); throat swab culture negative; chest radiograph was within normal limits; serial electrocardiograms were normal ; ASO titre 250 units $/ \mathrm{ml}$.

A tentative diagnosis of acute rheumatic fever was made and he was treated with intramuscular followed by oral penicillin. The rash disappeared in a few days and the nodule regressed completely over three weeks. The CFT to $M$. pneumoniae showed a fall from the diagnostic level of 1 in 128 on admission to 1 in 64 nine days later, indicating that the infection was recent. He continued to complain of pain in the right wrist and phalangeal joints for some weeks but he has remained well for over two years.

CASE 4 (Table) A boy aged 15 years developed a sore throat which was treated with oral penicillin. $\mathrm{He}$ was admitted to hospital two weeks later complaining of painful, tender, swollen ankles and knees. On examination he had a temperature of $101^{\circ} \mathrm{F}$.; there were bilateral effusions of both knees and ankles with erythema around both elbows. The pulse rate was $80 /$ minute with sinus rhythm. No other abnormal physical signs were noted.

Investigations Haemoglobin $14.2 \mathrm{~g} . / 100 \mathrm{ml}$., WBC $8,000 / \mathrm{cu}$. mm., ESR $106 \mathrm{~mm}$. (Westergren). Throat swab cultures negative ; blood cultures negative ; midstream urine cultures negative; Paul-Bunnell negative ; ASO titre 800 units $/ \mathrm{ml}$., chest radiograph within normal limits.

An initial diagnosis of acute rheumatic fever was made and penicillin and salicylates were started. During the following week his condition remained unchanged; there was no tachycardia and serial electrocardiograms were normal. His condition then worsened, the temperature rising to $102^{\circ} \mathrm{F}$. A repeat chest radiograph showed consolidation in the posterior segment of the left lower lobe. Ampicillin was substituted for penicillin without benefit. Three days later the CFT to $M$. pneumoniae was reported as greater than 1 in 1,280 whilst the CAT was 1 in 1,280 . After ampicillin had been replaced by tetracycline the temperature fell to normal within 24 hours, the patient making a rapid uneventful recovery. Two weeks later the CFT was 1 in 2,560 and the CAT 1 in 160. Salicylates were then discontinued. One month after treatment had finished the ASO titre was normal. He has remained perfectly well for over two years.

\section{DISCUSSION}

The four cases presented here are taken from a personally collected series of 110 cases of infection with $M$. pneumoniae. Either the lack of awareness of the disease or the absence of any characteristic clinical features often meant that early serological tests were omitted whilst cold agglutinins which might have allowed a tentative diagnosis to be made earlier in the illness were rarely looked for. Undoubtedly a major problem in early diagnosis was the unavoidable delay in obtaining positive serological evidence of infection. That the diagnosis was only established after recovery mattered little in most instances except that as a result treatment was haphazard: 13 patients were treated effectively with tetracycline, and a further 19 were given tetracycline later in the illness after a variety of other antibiotics had proved useless. 
Additional diagnostic difficulties arose in these four patients whose illness needed to be distinguished from other causes of arthralgia, notably rheumatic fever and rheumatoid arthritis. Each of the patients had pain in the joints and three had local joint swelling. Not surprisingly, a diagnosis of acute rheumatic fever was made in two and considered in a third. In case 1 the ASO titre was normal, there being no other support for the diagnosis. In case 3 cardiovascular signs were absent and the ASO titre and serial cardiograms were normal. The chest radiograph was also normal. The nodule remained unexplained but resolved spontaneously or as a result of treatment. Only a twofold fall in CFT was demonstrated and hence the diagnosis must remain in some doubt. In case 4 the evidence in favour of infection with $M$. pneumoniae seems overwhelming. Despite the raised ASO titre additional support for a diagnosis of rheumatic fever was lacking. High titres of cold agglutinins and complement fixing antibodies on admission, together with a dramatic response to tetracycline, suggest that the entire illness was due to $M$. pneumoniae. In case 2 rheumatoid arthritis was briefly considered but was never confirmed.

Similar diagnostic difficulties were encountered by Lambert (1968b), who described three patients in whom joint symptoms were predominant. All had radiological evidence of pneumonia, the diagnosis being established by complement fixation tests together with raised cold agglutinins in two. ASO titres in all three were low. He also drew attention to a fourth case referred to in a previous publication (George, Ziskind, Rasch, and Mogabgab, 1966).

That the joint manifestations might have a separate aetiology is possible but unlikely. Antibiotic sensitivity could be considered in cases 1 , 2 and 4 as either penicillin or tetracycline were given before the onset of joint symptoms. However, in none of them was there any other evidence of hypersensitivity. Lambert (1968b) likewise considered drug sensitivity but found no evidence of it. Since a common denominator in all cases except one was pneumonia, secondary bacterial infection could possibly be relevant. Nevertheless, bacterial invasion following infection with $M$. pneumoniae is rare and no pathogens were isolated from the sputum of any of these patients. Conversely, patients with pneumonia and arthritis may well be successfully treated with tetracycline, a bacterial cause thus being assumed, without $M$. pneumoniae being considered.
The diverse manifestations of infection with $M$. pneumoniae resemble quite closely those produced by other mycoplasma species in a wide variety of animals (Leading article, 1965). Amongst these arthralgia is prominent, occurring either alone, for example in pigs and rats, or as part of a generalized infection in goats (Darbyshire and Roberts, 1968). In man, certain species of human mycoplasma other than $M$. pneumoniae have been isolated from the joints of patients with rheumatoid arthritis and similar diseases but at present their significance remains speculative (Decker, 1966).

The true incidence of joint involvement following human infection with $M$. pneumoniae is unknown but must be extremely small. Nevertheless it seems to occur in Great Britain sufficiently often to warrant consideration, particularly in young patients, whenever a diagnosis of rheumatic fever proves difficult to substantiate. The therapeutic and possibly diagnostic value of tetracycline, as shown by cases 1 and 4, should also be borne in mind.

I wish to express my sincere thanks to Dr. J. E. Gates (Bristol Royal Infirmary), the late Dr. Evan Jones (St. Thomas' Hospital, London), Dr. A. F. Foster-Carter (Brompton Hospital, Frimley) and Dr. L. D. W. Scott (Southern General Hospital, Glasgow) for their kind permission to publish these cases. I should also like to thank Dr. N. C. Oswald for considerable help and encouragement.

\section{REFERENCES}

Chanock, R. M., Hayflick, L., and Barile, M. F. (1962). Growth on artificial medium of an agent associated with atypical pneumonia and its identification as a PPLO. Proc. nat. Acad. Sci. (Wash.), 48, 41 .

Darbyshire, J. H., and Roberts, D. H. (1968). Some respiratory virus and mycoplasma infections of animals. Symposium on Acute Respiratory Diseases (J. clin. Path., 21, Suppl. No. 2, p. 61).

Decker, J. L. (Ed.) (1966). Proceedings of the Conference on the relationship of Mycoplasma to rheumatoid arthritis and related diseases, February 10-11, 1966, Chicago, Illinois. U.S. Dept of Health, Education and Welfare.

George, R. B., Ziskind, M. M., Rasch, J. R., and Mogabgab, W. J. (1966). Mycoplasma and adenovirus pneumonias. Comparison with other atypical pneumonias in a military population. Ann. intern. Med., 65, 931 .

Gordon, A. M., and Lyell, A. (1969). Mycoplasmas and erythema multiforme. Lancet, $1,1314$.

Griffin, J. P., and Crawford, Y. E. (1969). Association of Mycoplasma pneumoniae infection with primary atypical pneumonia. Amer. Rev. resp. Dis., 100, 206.

Lambert, H. P. (1968a). Mycoplasma pneumoniae infections. Symposium on Acute Respiratory Diseases (J. clin. Path., 21, Suppl. No. 2, p. 52).

- (1968b). Syndrome with joint manifestations in association with Mycoplasma pneumoniae infection. Brit. med. J., 3, 156.

Leading Article (1965). Mycoplasmas. Brit. med. J., 2, 1499.

Peterson, O. L., Ham, T. H., and Finland, M. (1943). Cold agglutinins (autohemagglutinins) in primary atypical pneumonias. Science, 97, 167. 